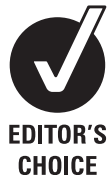

Wound Biology Group, Cardiff Institute of Tissue Engineering and Repair (CITER), Tissue Engineering and Reparative Dentistry, School of Dentistry, Cardiff University, Heath Park, Cardiff, UK

\section{Correspondence to J Hardwicke, Wound Biology Group, Cardiff Institute of Tissue Engineering and Repair (CITER), Tissue Engineering and Reparative Dentistry, School of Dentistry, Cardiff University, Heath Park, Cardiff CF14 4XY, UK: \\ hardwickej@doctors.org.uk}

Accepted 17 April 2010 Published Online First 9 September 2010

\title{
Investigation of the potential of polymer therapeutics in corneal re-epithelialisation
}

\author{
J Hardwicke, B Song, R Moseley, D W Thomas
}

\section{ABSTRACT}

In this study, the first use of a bioresponsive polymer therapeutic agent in the promotion of corneal reepithelialisation after injury in an ex vivo whole-eye organ culture model was described. A polymer-protein conjugate consisting of dextrin and recombinant human epidermal growth factor was synthesised and applied as a single dose to a $2 \mathrm{~mm}$ ex vivo corneal ulcer, in culture. Enhanced wound healing was observed in response to dextrin-recombinant human epidermal growth factor, when exposed to $\boldsymbol{\alpha}$-amylase, compared with controls. This highlights the potential for polymer therapeutics to provide a platform for bioresponsive drug/protein delivery in the field of ophthalmology.

\section{INNOVATION}

The descriptor 'polymer therapeutic' is an umbrella term used to describe polymeric drugs, polymer-drug conjugates, polyplexes, polymer-protein conjugates, and polymeric micelles, to which a drug can be bound. ${ }^{1}$ In the context of polymer-protein conjugates, the stability and solubility of proteins can be enhanced, and their biological half-life and immunogenicity reduced, via polymer conjugation. ${ }^{2} 3$ To this date, although polymer therapeutics have been licensed for use in humans (table 1), they have not been investigated widely in the field of corneal wound healing.

We have been developing a novel controlled release formulation of recombinant human epidermal growth factor (rhEGF), conjugated to the degradable polysaccharide, dextrin. ${ }^{4}$ This provides a controlled delivery platform for the release of rhEGF in response to endogenous $\boldsymbol{\alpha}$-amylase, which is present in the tear film. When conjugated to the dextrin polymer, the bioactivity of the growth factor is decreased, but an increase in protein stability is afforded. Bioactivity can be fully restored after polymer degradation by $\boldsymbol{\alpha}$-amylase, and the dextrin breakdown products, maltose, and isomaltose are further metabolised and/or excreted. ${ }^{6}$ This Polymer-masking UnMasking Protein Therapy hypothesis ${ }^{7}$ has been shown to stimulate dermal keratinocyte proliferation in vitro and enhances both the half-life of rhEGF and the stability in response to wound proteolysis. ${ }^{4}$

In animal studies, EGF stimulated proliferation and DNA synthesis of corneal epithelium and increased the epithelial healing rate. ${ }^{8-13}$ The initial hope of EGF to progress to a licensed product for clinical use in the early $1990 \mathrm{~s}^{14-16}$ did not come to fruition. The lack of significant effects from EGF, in humans, applied post penetrating keratoplasty ${ }^{17}$ did not match the previous findings from animal studies. The aforementioned clinical studies have involved the repeated administration of EGF because of the short half-life and the action of the tear film. ${ }^{18}$

\section{METHODS}

We have evaluated the efficacy of single dose dextrin-rhEGF in an ex vivo organ culture model of corneal wound healing. ${ }^{19} 20$ The synthesis and characterisation of the conjugate was reproducible (figure 1). ${ }^{4}$ Two-month-old male Wistar Han rats (250-300 g; Charles River Laboratories, Margate, UK) were sacrificed by $\mathrm{CO}_{2}$ asphyxiation, confirmed by cervical dislocation. Wounding was performed within $1 \mathrm{~h}$ of sacrifice. The globe was irrigated with Balanced Salt Solution (BSS Plus ${ }^{\circledR}$; Alcon Laboratories, Hemel Hemstead, UK) containing $0.1 \%$ EDTA. A full-thickness $2 \mathrm{~mm}$ corneal abrasion was produced by excision. The globe was then enucleated. Tissue culture medium (DMEM supplemented with penicillin G, $100 \mathrm{U} /$ $\mathrm{ml}$; streptomycin sulphate, $100 \mu \mathrm{g} / \mathrm{ml}$; amphotericin B, $0.25 \mu \mathrm{g} / \mathrm{ml}$; L-glutamine, $2 \mathrm{mM}$ (Invitrogen, Paisley, UK): serum-free media (SFM)) was supplemented with study compounds, as shown in table 2 , and added to the globes $(n=4)$. Specimens were maintained at $37^{\circ} \mathrm{C} / 5 \% \mathrm{CO}_{2}$ for $64 \mathrm{~h}$. Wound healing was assessed by digital wound photography and fluorescein staining. After $64 \mathrm{~h}$, globes were fixed in $10 \%$ formal saline, embedded in wax, sectioned and stained with H\&E. Statistical analyses were undertaken using GraphPad Prism ${ }^{\circledR}$, version 4.00 (GraphPad Software). Data were compared using a 1-way ANOVA, with a Bonferroni post test for group analysis. Results were expressed as a mean and SD. Statistical significance was considered at a probability of $\mathrm{p}<0.05$.

\section{RESULTS}

This ex vivo model of corneal wound healing was sensitive to stimulation by fetal calf serum and by dextrin-rhEGF. In the conjugated form, the rhEGF promoted a significant increase in the rate of corneal wound healing, with wound closure by $48 \mathrm{~h}$, in the presence of human physiological levels of $\alpha$-amylase compared with free rhEGF. With the addition of exogenous $\boldsymbol{\alpha}$-amylase, at physiological concentrations, rhEGF was released, or 'unmasked' from the polymer, thereby restoring bioactivity (figures 2 and 3 ).

There was a significant improvement in wound healing $(\mathrm{p}<0.006)$, in response to serum-containing medium (SCM; group 2), compared with the serum-free (SFM; group 1) and $\boldsymbol{\alpha}$-amylase (group 3) controls at $24 \mathrm{~h}$ (figure 4A). All wounds in the SCM group (group 2) had fully re-epithelialised by $48 \mathrm{~h}$, 
Table 1 Polymer therapeutics that are licensed in the UK

\begin{tabular}{lllll}
\hline Name & Manufacturer & Polymer Protein & Indication \\
\hline $\begin{array}{l}\text { Neulasta } \\
\text { (Pegfilgrastim) }\end{array}$ & $\begin{array}{l}\text { Amgen (Thousand } \\
\text { Oaks, California, USA) }\end{array}$ & PEG & GCSF & $\begin{array}{l}\text { Chemotherapy- } \\
\text { induced } \\
\text { neutropenia } \\
\text { Hepatitis C }\end{array}$ \\
$\begin{array}{l}\text { Pegasys } \\
\begin{array}{l}\text { (Peginterferon } \\
\text { alfa) }\end{array}\end{array}$ & $\begin{array}{l}\text { Roche (Basel, } \\
\begin{array}{l}\text { ViraferonPeg } \\
\text { (Peginterferon }\end{array}\end{array}$ & Peg & $\alpha$-IFN-2a & (Kenilworth, New \\
$\begin{array}{l}\text { alfa) } \\
\begin{array}{l}\text { Somavert } \\
\text { (Pegvisomant) }\end{array}\end{array}$ & $\begin{array}{l}\text { Jersey, USA) } \\
\text { Pfizer (New York, USA) PEG }\end{array}$ & PEG & $\alpha$-IFN-2b & Hepatitis C \\
& & $\begin{array}{l}\text { hormon growth } \\
\text { antagonist }\end{array}$ & Acromegaly \\
\hline
\end{tabular}

GCSF, granulocyte colony stimulating factor; IFN, interferon; PEG, polyethylene glycol. while the average wound areas in the serum-free controls (groups 1 and 3 ) were $24.5 \pm 8.1 \%$ and $31.4 \pm 5 \%$, respectively, of that at time $0 \mathrm{~h}(\mathrm{p}<0.001)$. In the unconjugated rhEGF groups (groups 4 and 5), there were no significant effects on wound reepithelialisation $(p>0.05)$ at either concentration and neither resulted in total wound re-epithelialisation. Wound areas at $64 \mathrm{~h}$ were $5.6 \pm 11.3 \%$ and $23.4 \pm 21.4 \%$ of the total wound area at time $0 \mathrm{~h}$ for the $10 \mu \mathrm{g} / \mathrm{ml}$ rhEGF and $1 \mu \mathrm{g} / \mathrm{ml}$ rhEGF groups, respectively (mean $\pm \mathrm{SD}$ ) (figure $4 \mathrm{~B})$.

In the dextrin-rhEGF conjugate study groups (groups 6-8), there was failed re-epithelialisation, in the absence of physiological concentrations of $\boldsymbol{\alpha}$-amylase (group 6; 'masked'), with an abrasion of $23.4 \pm 5.5 \%$ of that at time 0 , persisting at $64 \mathrm{~h}$. This was not significantly different to the SFM control (group 1) ( $p>0.05)$. Upon the addition of $\alpha$-amylase ( $93 \mathrm{IU} / \mathrm{l}$; 'unmasking'), there was a significant decrease in the wound area
Figure 1 The Polymer-masking UnMasking Protein Therapy (PUMPT) hypothesis. Succinoylated dextrin is conjugated to recombinant human epidermal growth factor (rhEGF) using EDC and sulfo-NHS cross-linkers to produce a dextrin-rhEGF polymer-protein conjugate. On exposure to $\alpha$-amylase (present in human tear fluid), bioactive rhEGF is released from the polymer in a controlled release fashion. rhEGF would induce corneal epithelial cell proliferation and migration, whilst the polymer would be metabolised to the maltose and isomaltose disaccharide units. RT, room temperature.
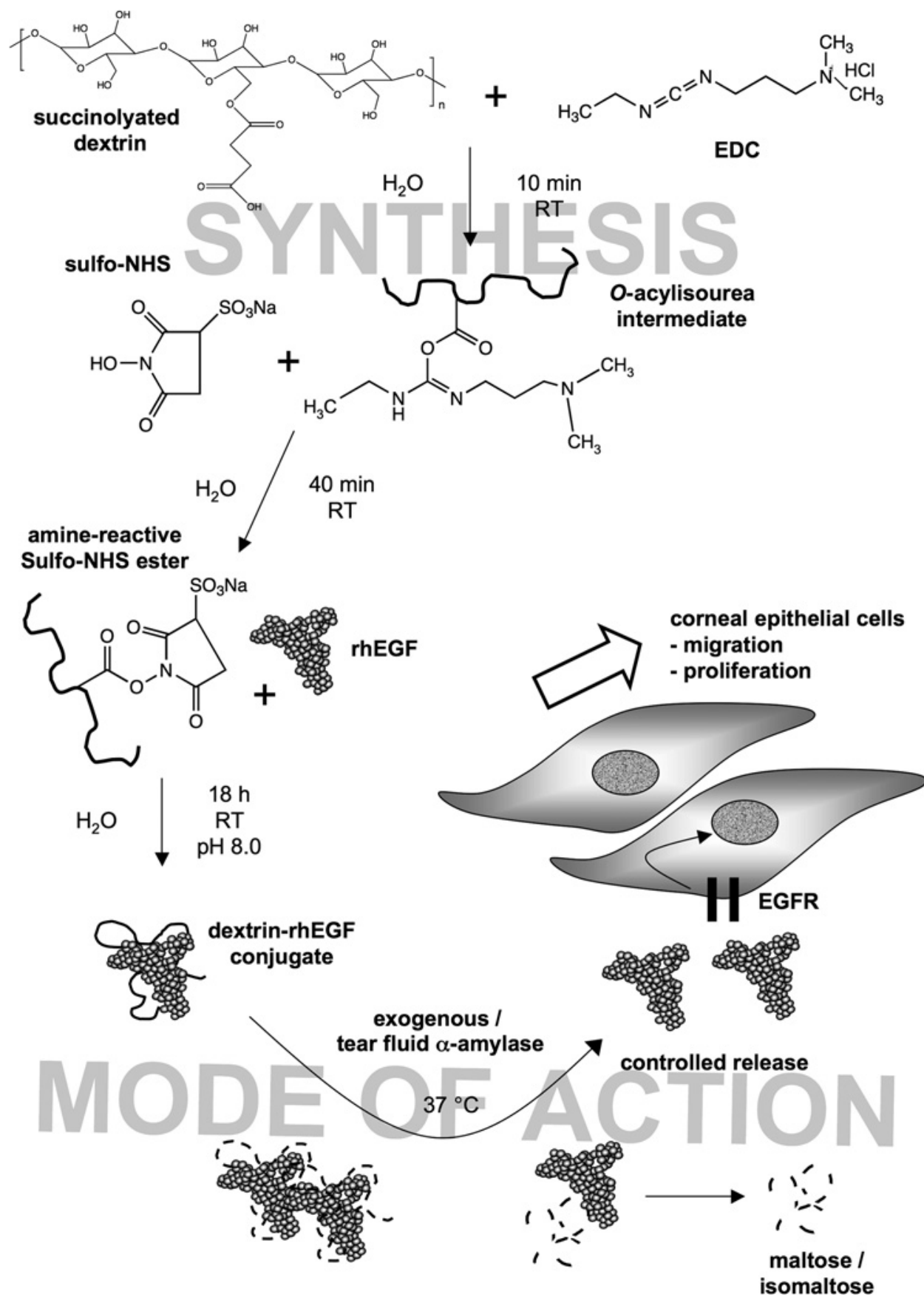
Table 2 Culture medium supplementation

\begin{tabular}{|c|c|}
\hline Group & Supplement \\
\hline 1 & - \\
\hline 2 & 10\% FCS (Invitrogen, Paisley, UK) \\
\hline 3 & $\alpha$-amylase (93 IU/l, Sigma-Aldrich, Poole, UK) \\
\hline 4 & rhEGF $(1 \mu \mathrm{g} / \mathrm{ml})$ \\
\hline 5 & rhEGF $(10 \mu \mathrm{g} / \mathrm{ml})$ \\
\hline 6 & Dextrin-rhEGF ( $1 \mu \mathrm{g} / \mathrm{ml}$ rhEGF equivalent in PBS) \\
\hline 7 & $\begin{array}{l}\text { Dextrin-rhEGF }(1 \mu \mathrm{g} / \mathrm{ml} \text { rhEGF equivalent in PBS) and } \alpha \text {-amylase (93 IU/l) } \\
\text { (pre-incubated for } 24 \mathrm{~h} \text { at } 37^{\circ} \mathrm{C} \text { ) }\end{array}$ \\
\hline 8 & $\begin{array}{l}\text { Dextrin-rhEGF (10 } \mu \mathrm{g} / \mathrm{ml} \text { rhEGF equivalent in PBS) and } \alpha \text {-amylase (93 IU/l) } \\
\text { (pre-incubated for } 24 \mathrm{~h} \text { at } 37^{\circ} \mathrm{C} \text { ) }\end{array}$ \\
\hline
\end{tabular}

FCS, fetal calf serum; PBS, phosphate buffered saline; rhEGF, recombinant human epidermal growth factor.

at $24 \mathrm{~h}$ in both the $1 \mu \mathrm{g} / \mathrm{ml} \mathrm{rhEGF} \mathrm{equivalent} \mathrm{(group} \mathrm{7)} \mathrm{and}$ $10 \mu \mathrm{g} / \mathrm{ml} \mathrm{rhEGF}$ equivalent (group 8) groups $(\mathrm{p}<0.006$ ). The dextrin-rhEGF conjugate was significantly more effective at decreasing the wound area at $24 \mathrm{~h}$ at the lower dose $(1 \mu \mathrm{g} / \mathrm{ml}$ rhEGF equivalent) than at the higher dose $(10 \mu \mathrm{g} / \mathrm{ml} \mathrm{rhEGF}$ equivalent) ( $\mathrm{p}=0.027$ ) (figure $4 \mathrm{C})$.

\section{DISCUSSION}

The increased efficacy of the dextrin-rhEGF conjugate in enhancing corneal wound healing may be due to the sustained release phenomena. ${ }^{4}$ In the ex vivo model described herein, the rhEGF was applied as a single dose at the outset of the experiment, and the free rhEGF may have been degraded because of the short half-life of EGF. ${ }^{18}$ Although initial wound closure rates are similar in the first $24 \mathrm{~h}$ between rhEGF and dextrin-rhEGF $(+\alpha$-amylase), this apparent difference tailed off as time progressed. In the ex vivo organ culture model, the pharmacokinetics of EGF will differ but the sustained release of rhEGF from the $\alpha$-amylase-mediated, degradation of the dextrin-rhEGF conjugate may account for the enhanced wound healing in the
Figure 2 Typical ex vivo corneal wound closure images. (A) Healing of the corneal abrasion in serum-free conditions over $64 \mathrm{~h}$. (B) Healing of the corneal abrasion in $10 \%$ fetal calf serum (FCS) - supplemented media. ( $\mathrm{C}-\mathrm{H})$ Typical fluorescein staining of the corneal wound in the remaining study groups at $48 \mathrm{~h}$.

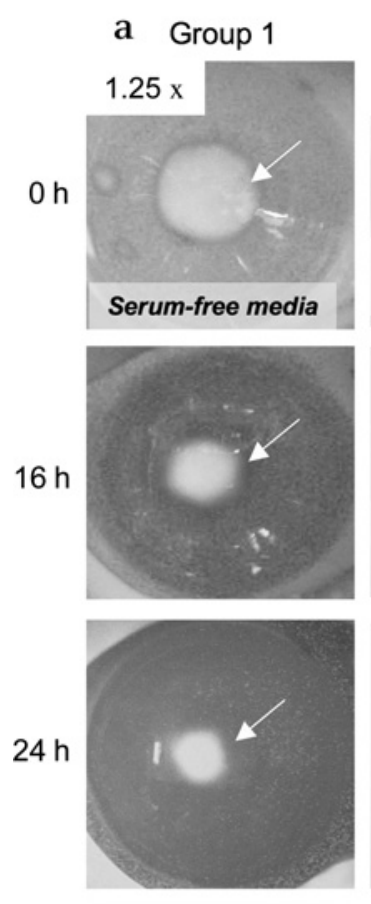

\section{b Group 2}

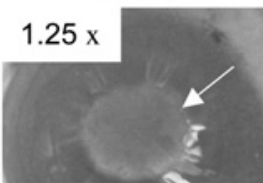

$10 \%$ Serum-containing media
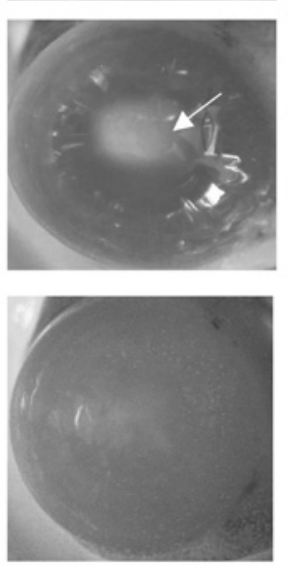

$48 \mathrm{~h}$
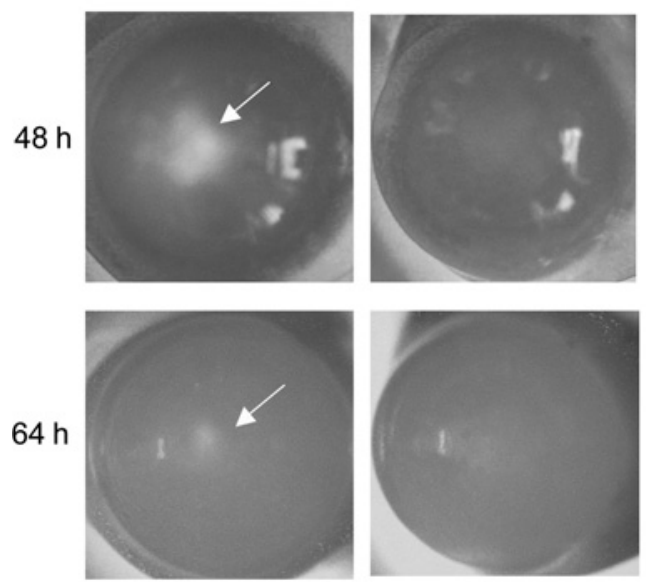

C Group 3

$\alpha$-amylase (93 IU/I)

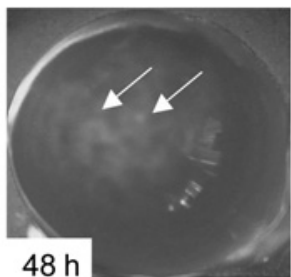

d Group 4 rhEGF $(1 \mu \mathrm{g} / \mathrm{ml})$

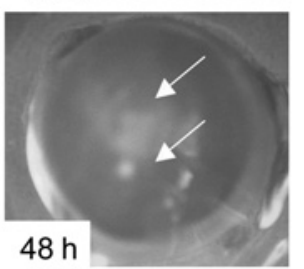

e Group 5
$\operatorname{hEGF}(10 \mu \mathrm{g} / \mathrm{ml})$

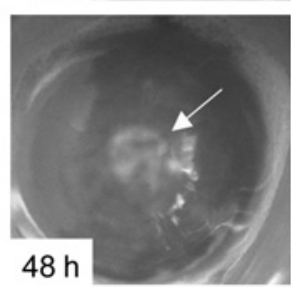

f Group 6

Dextrin-rhEGF $(10 \mu \mathrm{g} / \mathrm{ml})$

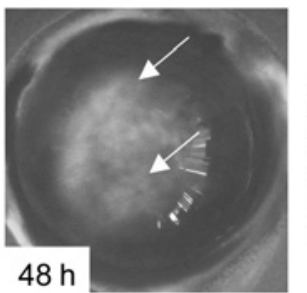

g Group 7

Dextrin-rhEGF $(1 \mu \mathrm{g} / \mathrm{ml})$

h Group 8

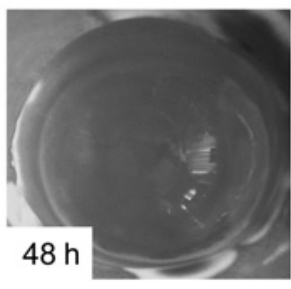

Dextrin-rhEGF $(10 \mu \mathrm{g} / \mathrm{ml})$ 
Figure 3 (A) Haematoxylin/eosin staining of a section through a corneal abrasion in the absence of fetal calf serum (FCS). (B) Haematoxylin/eosin staining of a section through a region of corneal abrasion in presence of FCS. Both specimens were harvested at $64 \mathrm{~h}$. The corneal wound is still evident in the absence of FCS supplementation (Wm, wound margin) (magnification $\times 20$ ).

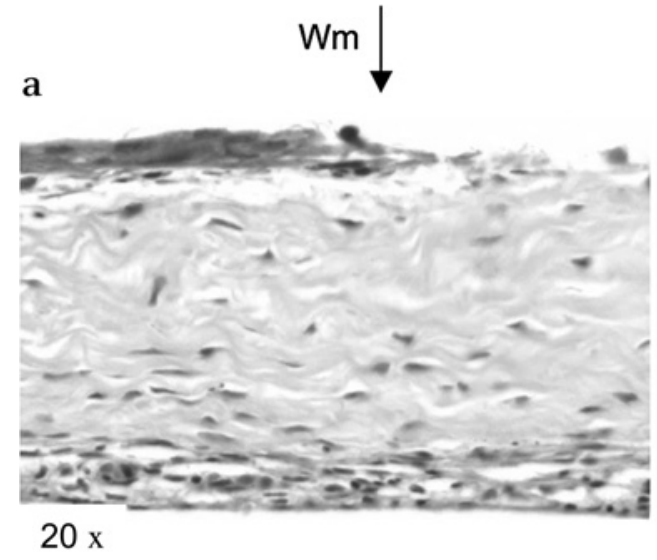

b
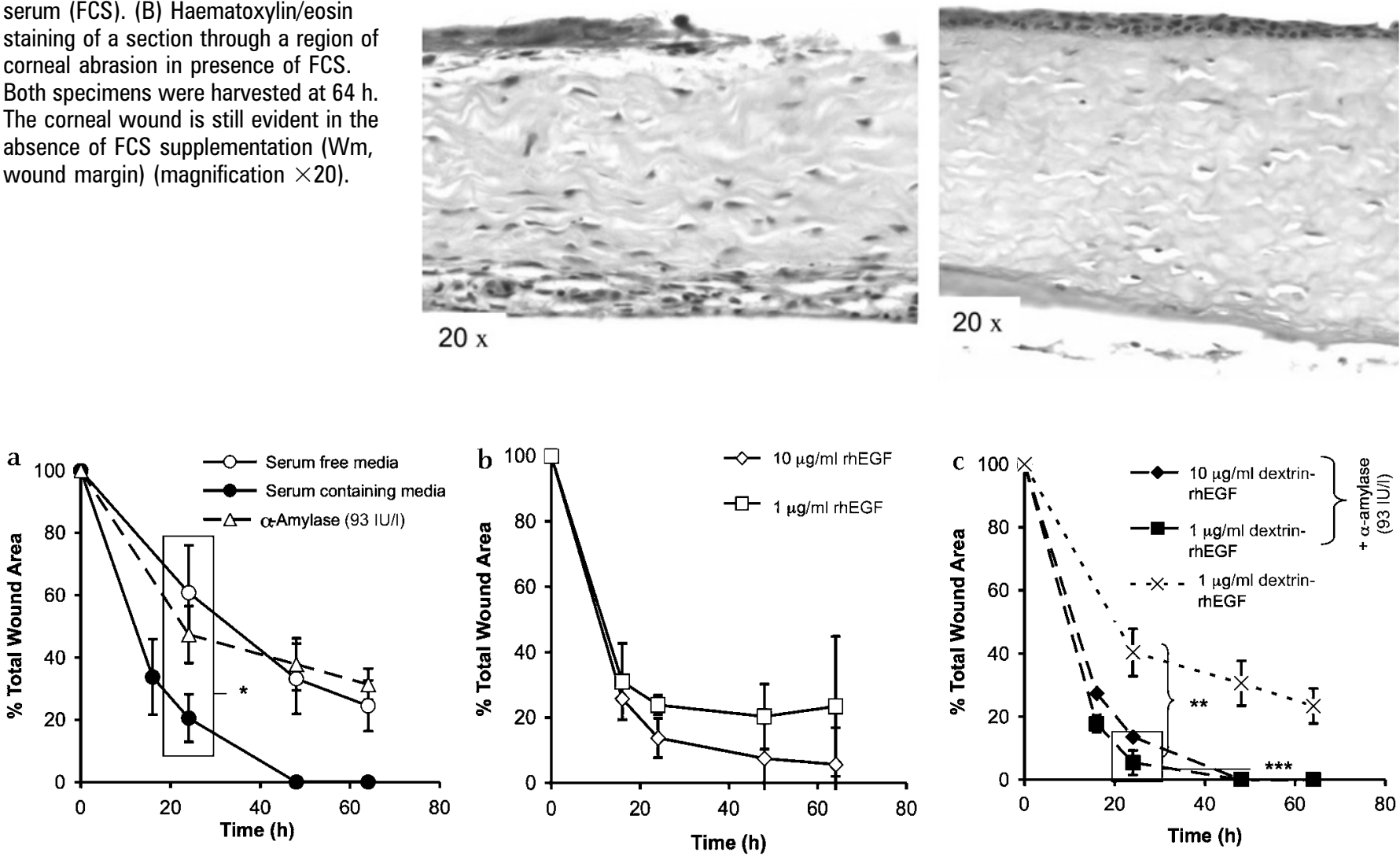

Figure 4 (A) Healing of the corneal wound (\% reduction in wound area compared to $0 \mathrm{~h}$ ) over $64 \mathrm{~h}$ in response to fetal calf serum (FCS) (serumcontaining media) and serum-free controls. There was a significant decrease $\left({ }^{*} p<0.006\right)$ in the wound area in response to FCS when compared with serum-free controls. (B) The corneal wound area reduction in response to free recombinant human epidermal growth factor (rhEGF). The initial rate of wound area reduction (over the first $24 \mathrm{~h}$ ) was not significantly different ( $p>0.05)$ from FCS, but the effect was not sustained over $64 \mathrm{~h}$. (C) The corneal wound area reduction in response to dextrin-rhEGF. In the 'masked' ( $\alpha$-amylase-free) state, the bioactivity of dextrin-rhEGF was reduced to that of serum-free controls $(p>0.05)$, but upon the addition of $\alpha$-amylase at physiological concentrations, bioactivity was significantly restored $\left({ }^{* *} \mathrm{p}<0.006\right.$ ). Dextrin-rhEGF was most effective at the $1 \mu \mathrm{g} / \mathrm{ml}$ concentration ( ${ }^{* *} \mathrm{p}=0.027$ ) compared with the conjugate at $10 \mu \mathrm{g} / \mathrm{ml}$ concentrations.

dextrin-rhEGF study groups. The ex vivo model of corneal wound healing has been shown to be reproducible and that it is a reliable model for further analysis of polymer-protein conjugates. This is the first application of polymer therapeutics specifically designed for tissue regeneration in such a model, and these preliminary investigations highlight the potential for the application of these therapeutics to enhance corneal wound healing. This application of a specific endogenous trigger to promote the controlled release of a bioactive peptide may be applied to the healing and/or regeneration of other tissues in the future.

Acknowledgements The authors would like to acknowledge support from EPSRC platform grant No. EP/C 013220/1.

Funding JH was funded by a Fellowship from The Healing Foundation (Registered Charity No. 1078666) and the Welsh Office for Research and Development (WORD).

Competing interests None.

Provenance and peer review Not commissioned; externally peer reviewed.

\section{REFERENCES}

1. Duncan R. The dawning era of polymer therapeutics. Nat Rev Drug Discov 2003;2:347-60.
2. Veronese FM, Harris JM. Introduction and overview of peptide and protein pegylation. Adv Drug Deliv Rev 2002;54:453-6.

3. Veronese FM, Pasut G. PEGylation, successful approach to drug delivery. Drug Discov Today 2005;10:1451-8

4. Hardwicke J, Ferguson EL, Moseley R, et al. Dextrin-rhEGF conjugates as bioresponsive nanomedicines for wound repair. J Control Release 2008:130:275-83.

5. van Haeringen NJ, Ensink F, Glasius E. Amylase in human tear fluid: origin and characteristics, compared with salivary and urinary amylases. Exp Eye Res 1975;21:395-403.

6. Peers $\mathbf{E}$, Gokal R. Icodextrin provides long dwell peritoneal dialysis and maintenance of intraperitoneal volume. Artif Organs 1998:22:8-12.

7. Duncan R, Gilbert HR, Carbajo RJ, et al. Polymer masked-unmasked protein therapy 1. Bioresponsive dextrin-trypsin and -melanocyte stimulating hormone conjugates designed for alpha-amylase activation. Biomacromolecules 2008;9:1146-54

8. Frati L, Daniele S, Delogu A, et al. Selective binding of the epidermal growth factor and its specific effects on the epithelial cells of the cornea. Exp Eye Res 1972;14:135-41.

9. Savage CR, Cohen S. Proliferation of corneal epithelium induced by epidermal growth factor. Exp Eye Res 1973;15:361-6.

10. Ho PC, Davis WH, Elliott JH, et al. Kinetics of corneal epithelial regeneration and epidermal growth factor. Invest Ophthalmol Vis Sci 1974:13:804-9.

11. Watanabe K, Nakagawa S, Nishida T. Stimulatory effects of fibronectin and EGF on migration of corneal epithelial cells. Invest Ophthalmol Vis Sci 1987;28:205-11.

12. Singh G, Foster CS. Epidermal growth factor in alkali burned corneal epithelial wound healing. Am J Ophthalmol 1987;103:802-7.

13. Gönül B, Erdoğan D, Ozoğul C, et al. Effect of EGF dosage forms on alkali burned corneal wound healing of mice. Burns 1995;21:7-10. 
14. Caporossi A, Manetti C. Epidermal growth factor in topical treatment following epikeratoplasty. Ophthalmologica 1992;205:121-4

15. Scardovi C, De Felice GP, Gazzaniga A. Epidermal growth factor in the topical treatment of traumatic corneal ulcers. Ophthalmologica 1993;206:119-24.

16. Cellini M, Baldi A, Caramazza N, et al. Epidermal growth factor in the topical treatment of herpetic corneal ulcers. Ophthalmologica 1994;208:37-40.

17. Dellaert MM, Casey TA, Wiffen S, et al. Influence of topical human epidermal growth factor on postkeratoplasty re-epithelialisation. Br J Ophthalmol 1997;81:391-5.
18. Chan KY, Lindquist TD, Edenfield MJ, et al. Pharmacokinetic study of recombinant human epidermal growth factor in the anterior eye. Invest Ophthalmol Vis Sci 1991;32:3209-15.

19. Ramaesh T, Ramaesh K, Leask R, et al. Increased apoptosis and abnormal wound healing responses in the heterozygous Pax6+/- mouse cornea. Invest Ophthalmol Vis Sci 2006;47:1911-17.

20. Reid B, Song B, McCaig CD, et al. Wound healing in rat cornea: the role of electric currents. FASEB J 2005;19:379-86. 